\title{
ERÄIDEN SOIJALAJIKKEIDEN FOTOBIOLOGISISTA OMINAISUUKSISTA
}

\author{
Onni Pohjakallio ja Simo Antila \\ Helsingin yliopiston Kasvipatologian Laitos, Helsinki
}

Saapunut 14. 3. 1957

Soija on lyhyen päivän kasvi. Suomen pitkä kesäpäivä viivästyttää sen kehitystä. Jokioisissa suoritetuissa kokeissa ${ }^{1}$ ) todettiin kuitenkin eri soija-lajikkeiden fotoperiodisissa ominaisuuksissa suuria eroavaisuuksia. Manitoba-soijaan päivän pituudella oli suhteellisen pieni vaikutus, mutta sekään ei v. 1943 suoritetuissa kenttäkokeissa antanut siemensatoa. Helsingin yliopiston Viikin koetilalla on vuosina 1947-1953 seurattu Manitoba-soijan ohella Aro-soijan kehitystä pienissä kenttäkokeissa; v. 1953 oli kokeissa mukana myös Pando-soija. Kun soija ei yleensä tuleentunut, ei kokeita enää v. 1954 jatkettu. Saadut tulokset muodostuivat kuitenkin mielenkiintoisiksi sen johdosta, että v. 1954 monet soija-jalosteet eivät myöskään Norrköpingissä, Ruotsissa, muodostaneet sanottavasti siemeniä. Ruotsalainen soijanjalostaja HoLmBERG ${ }^{2}$ ) otaksui tämän ainakin osittain johtuneen suuren pilvisyyden aiheuttamasta valon niukkuudesta. Myöhemmin HoLMBerG ystävällisesti lähetti tutkimuksiamme varten siemeniä Pando-soijasta ja soijajalosteestaan "Fiskeby 843-15-4», jotka hänen ilmoituksensa mukaan kukkivat normaalisesti Norrköpingissä myös v. 1954 ja jalosteestansa "Fiskeby $846--2-1$, jonka kukinta oli silloin hyvin niukkaa.

Ruotsista saatuja soijia tutkittiin laboratoriossa ja kentällä. Laboratoriokokeissa soija kylvettiin Mitscherlich-astioihin, kuhunkin astiaan 10 siementä. Taimistumisen jälkeen osa taimista poistettiin siten, että varsinaisena koeaikana taimiluku kaikissa astioissa oli 5. Astiat sijoitettiin kahteen huoneeseen, eri etäisyyksille lähes kaakonsuuntaisista ikkunoista (kuva 1). Keskimääräinen päivänvalon voimakkuus oli ikkunaa lähinnä olleiden astiain kohdalla $62 \%$, kauimpain astiain kohdalla $25 \%$ ulkovaloisuudesta. Päivänvaloa saivat koekasvit vuorokausittain 10 tunnin ajan; muuksi vuorokauden ajaksi ikkuna peitettiin pimennysverholla. Toisessa huoneessa soija sai pimennysaikana valoa päivänvalolampuista n. 1000 luxia, joten valojakso muodostui yhtämittaiseksi. Siinä huoneessa, jossa vuorokausittaisen valojakson pituus oli 10 tuntia, soija sai valojakson aikana päivänvalon

(1) Pohjakallio, Onni 1945. Soijapavusta (Glycine hispida Max). Luonnon Ystävä 49: 24 -28.

(2) Holmberg, Sven A. 1956. Soya-bean adaption in Sweden. World Crops 8, No. 3. 
lisäksi keinovaloa niin paljon, että koko valoannos molemmissa huoneissa muodostui keskenään samaksi. Keskilämpötila oli lyhyen valojakson huoneessa +24.9 $\mathrm{C}^{\circ}$, pitkän valojakson huoneessa $+24.8 \mathrm{C}^{\circ}$. - Kylvö suoritettiin $19 / 3$, fotoperiodinen käsittely aloitettiin 23/3, sato korjattiin 6/6 1956 .

Sama soija-aineisto kylvettiin kenttäkokeeseen 5/6 1956, kukin soija kahteen koeruutuun, toiseen ymppäämättömänä, toiseen soijan nystyräbakteereilla käsiteltynä. Käsiteltyjen koeruutujen kasvustot olivat vihreämpiä kuin käsittelemättömien; samalla soijan kehitys nystyräbakteeriymppäyksen vaikutuksesta hidastui. Palkojen muodostumisen alkamista nystyräbakteeriymppäys viivästytti 4-14 päivää, Pando-soijassa vähiten. Jokioisissa v. 1943 suoritetuissa kokeissa, joissa tutkittiin toisia soija-lajikkeita, nystyräbakteeriymppäyksellä ei ollut näkyvää vaikutusta soijan kehitykseen ${ }^{1}$ ). - Tähän, samoin kuin vuosina $1947-1953$ suoritettuihin kenttäkokeisiin soija kylvettiin $10 \mathrm{~cm}$ :n etäisyyksin, $40 \mathrm{~cm}: n$ rivivälein.

Laboratoriokokeiden tuloksista ilmenee, että t ut kitut s o ijat olivat 1 äh es päiväneutra a lis i a (taulukko 1). Lyhyt valojakso joudutti kukinnan alkamista vain $2-3$ päivällä. Jokseenkin vastaavan suuruisena, joskin osittain erisuuntaisena, valojakson pituuden vaikutus ilmeni myös lehtien kellastumisessa, lehtien varisemisen aikaisuudessa ja muissa tuleentumisilmiöissä. Fiskebyn jalosteisiin valojakson pituuden vaikutus oli keskenään hyvin samansuuntainen, joskin ne muussa suhteessa erosivat toisistaan siten, että Fiskeby $846-2-1$ kasvoi selvästi korkeammaksi ja tuleentui hiukan aikaisemmin kuin Fiskeby 84315-4. Viimeksimainittu ilmeni ehkä selvimmin siemensadon vesipitoisuuserona. - Sen sijaan Pando reagoi valojakson pituuden vaikutuksesta selvästi eri tavalla kuin Fiskebyn jalosteet. Päinvastoin kuin nämä, Pando antoi suuremman siemensadon, tuleentui myöhemmin ja kasvoi korkeammaksi pitkän kuin lyhyen päivän olosuhteissa. Pandon lehdistö oli vihreä vielä ensimmäisten siementen tuleennuttua; Fiskebyn jalosteiden lehdistö kellastui suhteellisesti aikaisemmin.

Valoisuuden pienentyminen aiheutti soijan kukinnan alkamisen ja siemensadon tuleentumisen viivästymisen, kasvuston korkeuden suurenemisen sekä palkoja siemensadon alenemisen (taulukot 2 ja 3 ). Jo suurimmissakin laboratoriovaloisuuksissa on Fiskebyn soija-jalosteissa ilmennyt etioloitumisen symptomeja (kuva 2) ja taipumusta köynnöstävään kasvutapaan; pienimmissä valoisuuksissa on ilmeisesti valoenergian puute kuitenkin ollut syynä suhteellisen matalaan kasvuun. Pandossa puolestaan ei ole ilmennyt sanottavaa etioloitumista eikä myöskään kasvuston korkeuden pienentymistä pienimmissä valoisuuksissa. Sen varsisto ei siis ole ollut herkkä valon voimakkuuden muutoksille. Sen sijaan sen siemensato on jäänyt suhteellisesti pienimmäksi ja myös koevaloisuuksien puitteissa on valoisuuden väheneminen suhteellisesti haitallisimmin vaikuttanut sen siemensadon määrään. Vastaavasti myös Pandon palkojen luku (5 yksilöä kohden) on valon voimakkuuden vähentyessä pienentynyt suhteellisesti eniten: Fiskeby $846-2-1: 35$, 30, 25, 20, 20, 14; Fiskeby 843-15-4: 43, 31, 25, 20, 12, 9; Pando: 22, 14, 13, 6, 3, 5. Näiden koetulosten perusteella on pääteltävissä, että k e n t tä ol o s u hteissa ilmenevät valoisuuden vaihtelut tuskin voivat ratkaisevasti vaikuttaa soijan siemensadon määrän.

1) Kts. kirjallisuusviittaus 1, siv. 113. 

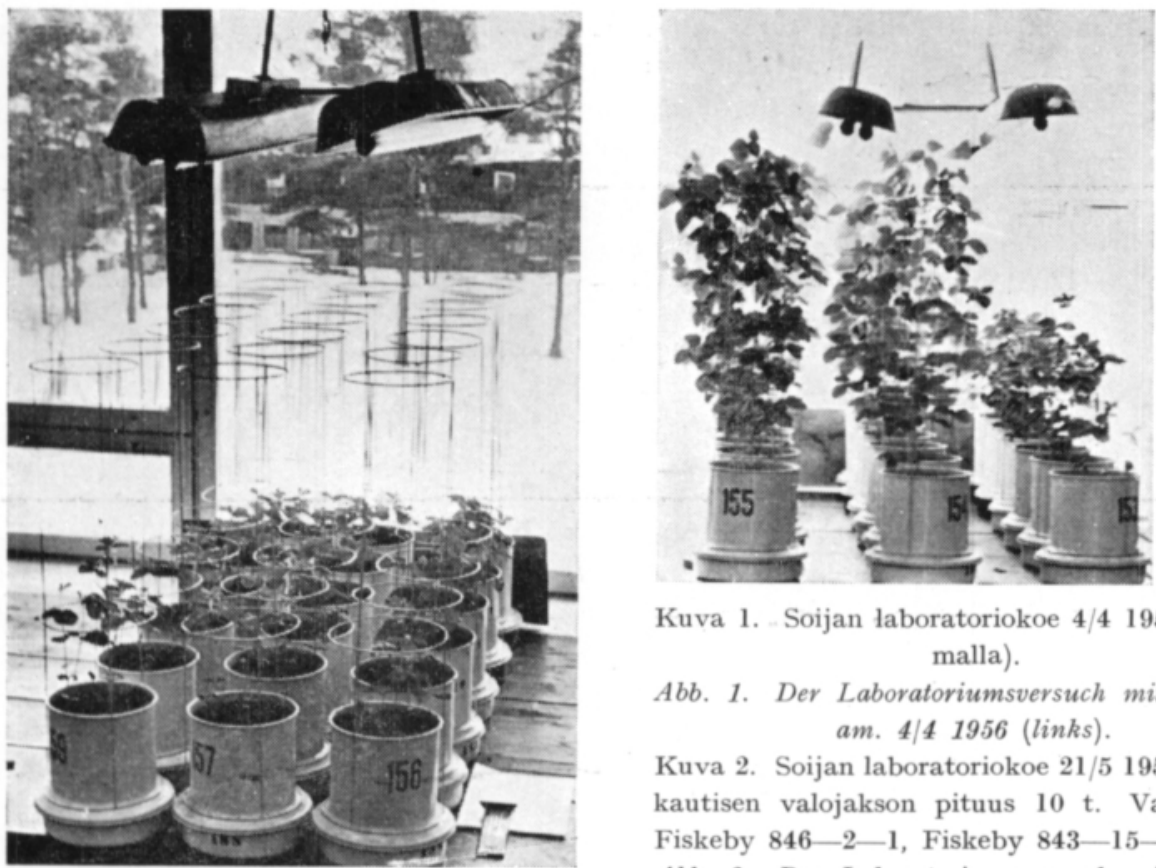

Kuva 1. Soijan laboratoriokoe 4/4 1956 (vasemmalla).

Abb. 1. Der Laboratoriumsversuch mit Soja am. 4/4 1956 (links).

Kuva 2. Soijan laboratoriokoe 21/5 1956. Vuorokautisen valojakson pituus $10 \mathrm{t}$. Vasemmalta: Fiskeby $846-2-1$, Fiskeby $843-15-4$, Pando. Abb. 2. Der Laboratoriumsversuch mit Soja am 21/5 1956. Dauer der täglichen Photoperiode $10 \mathrm{St}$. Von links an: Fiskeby 846-2-1, Fiskeby 843-15-4, Pando.

Laboratoriokokeissa lämpötila on nimittäin ollut varsin korkea, lähes $25 \mathrm{C}^{\circ}$, joten hengityksessä kulunut energiamäärä on ilmeisesti ollut suhteellisesti paljon suurempi kuin ulkona. Tästä huolimatta on soija yleensä muodostanut palkoja pienimmässäkin tutkitussa valoisuudessa kasvaneena. Sitä paitsi valon niukkuudella on ollut haitallisin vaikutus Pandon ja toiseksi haitallisin vaikutus Fiskeby $843-15-$ 4:n siemensatoon; vähäisimpänä on valon voimakkuuden väheneminen ilmennyt Fiskeby 846-2-1:ssä, joka Norrköpingissä, pilvisenä kesänä 1954, muodosti siemeniä erityisen niukasti.

Viikin koetilalla v. 1956 suoritetussa kenttäkokeessa (vastaavasti kuin Ruotsissa v. 1954) Pando ja Fiskeby 843-15-4 antoivat selvästi suuremman siemensadon kuin Fiskeby 846-2-1 (taulukko 4). Tosin näiden kaikkien soijien sato oli niukka, eikä läheskään ehtinyt tuleentua. Pilvisyys ei kesällä 1956 ollut erityisen suuri, mutta lämpötila oli sangen alhainen (taulukko 5). Siten näyttää siltä, että soijan siemensadon puutteelliseen kehitykseenkentällä on lämpötilalla ollut ratkaisevasti suurempi vaikutus kuin valon voimakku della.

Tätä käsitystä tukevat myös vuosina 1947-1953 suoritettujen kenttäkokeiden tulokset (taulukko 6). Siemensatoa on soijasta saatu vain kolmena kesänä, vuosina 1947, 1948 ja 1949. Lämpötilasuhteet ovat näinä kesinä olleet suotuisimmat (taulukko 7), kaikkein edullisimmat v. 1947, jolloin sato oli runsain ja sen itävyyskin moitteeton. Lämpötilan vaihtelut vuodesta toiseen eivät tosin olleet suuret, mutta kun lämpötila lienee kautaaltaan ollut lähellä soijan kehitykselle 
Taulukko 1. Valojakson pituuden vaikutus soijapavun eräisiin ominaisuuksiin. Kylvetty 19/3; fotoperiodinen käsittely aloitettu 23/3.

Tabelle 1. Die Wirkung der Dauer der Photoperiode auf einige Eigenschaften der Sojabohìe. Gesät am 19.3; photoperiodische Behandlung am 23.3. begonnen.

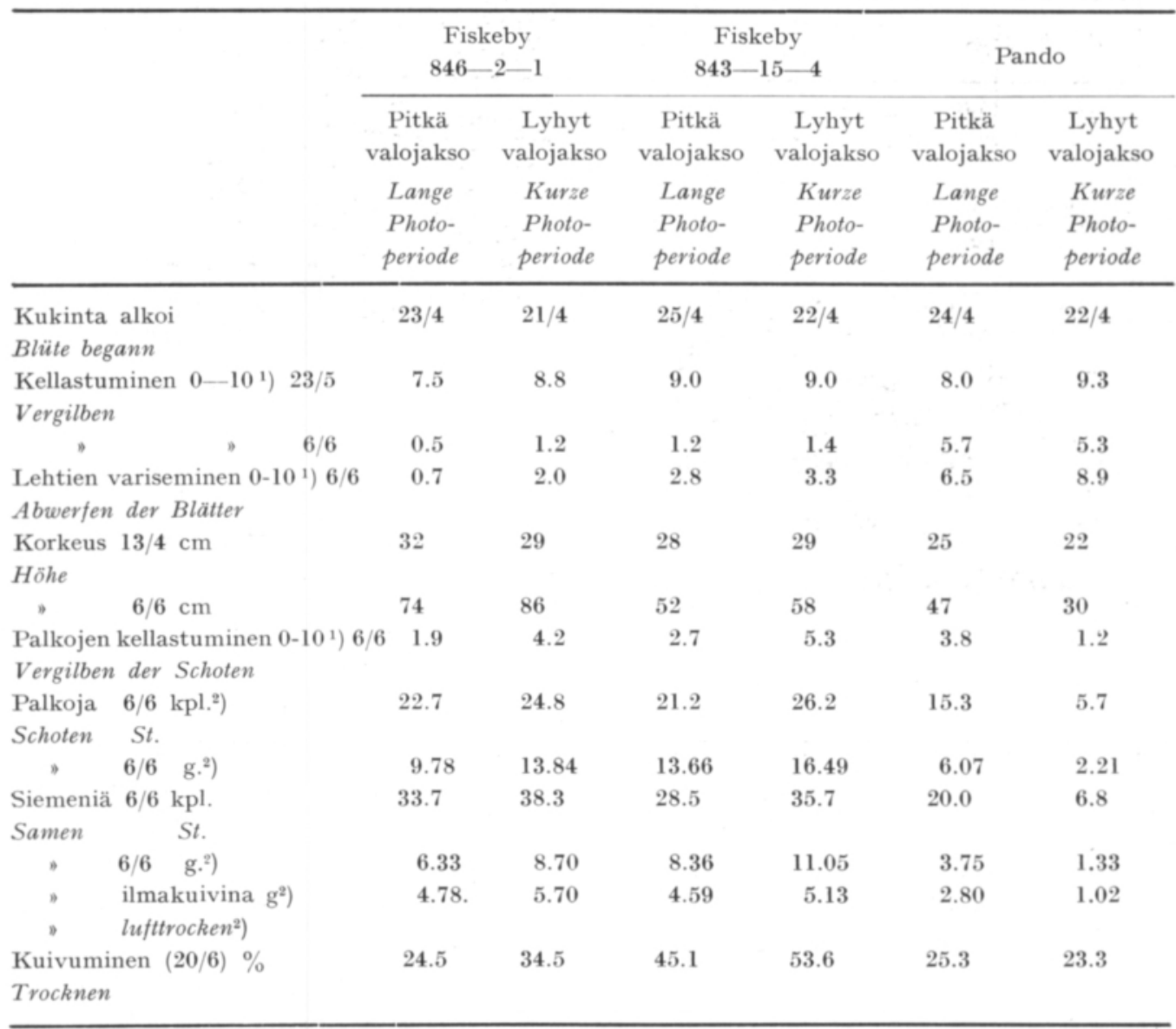

1) $10=$ vihreä resp. lehdet eivät varisseet.

1) $10=$ grün bzw. Blätter nicht abgeworfen.

2) Sadot ilmaistu 5 yksilöä kohden.

2) Erträge je 5 Individuen.

kriitillistä rajaa, on vähäinenkin lämpötilan aleneminen saattanut muodostua ratkaisevaksi, kun se on sattunut soijan jonkin erityisen kriitillisen kehitysvaiheen aikana. V. 1951, jolloin lämpötila heinäkuuta lukuunottamatta oli yhtä korkea kuin suotuisimpina vuosina, kylvöajan viivästymisellä oli sadon tuleentumiseen nähtävästi hyvin ratkaiseva vaikutus. - Aro-soija osoittautui Manitoba-soijaa vähän aikaisemmaksi.

Esitetyt koetulokset ovat sopusoinnussa RUDORFIn (vrt. Holmberg, s. 113) esittämän käsityksen kanssa, että Fi skebyn lähes päiväne u tra a listen soijajalosteiden viljelyn pohjoisraja a ei mä rää pitkä pä i vä, va a n lha in en 1 ämpöt i la. Sitä paitsi on ilmennyt, että va lon 
Taulukko 2. Valon voimakkuuden vaikutus soijapavun kehitykseen. Kylvetty 19/3.

Tabelle 2. Die Wirkung der Lichtstärke auf die Entwicklung der Sojabohne. Gesät am 19/3.



1) $10=$ palko vielä vihreä

1) $10=$ Schote noch grün

Taulukko 3. Valon voimakkuuden vaikutus soijapavun palko- ja siemensatoon.

Tabelle 3. Die Wirkung der Lichtstärke auf den Schoten- und Samenertrag der Sojabohne.

\begin{tabular}{|c|c|c|c|c|c|c|c|c|c|}
\hline \multirow{4}{*}{$\begin{array}{c}\text { Valoisuus- } \\
\text { ulkovaloi- } \\
\text { suudesta } \\
\% \\
\text { Belichtung } \\
\% \text { der } \\
\text { Aussen- } \\
\text { belichtung }\end{array}$} & \multicolumn{3}{|c|}{ Fiskeby $846-2-1$} & \multicolumn{3}{|c|}{ Fiskeby $843-15-4$} & \multicolumn{3}{|c|}{ Pando } \\
\hline & $\begin{array}{c}\text { Palkoja } \\
\text { (g) }\end{array}$ & $\begin{array}{c}\text { Ilma- } \\
\text { kuivia } \\
\text { siemeniä } \\
\text { (g) }\end{array}$ & $\begin{array}{l}\text { Siemenen } \\
\text { kuivumi- } \\
\text { nen }(\%)\end{array}$ & $\begin{array}{c}\text { Palkoja } \\
\text { (g) }\end{array}$ & $\begin{array}{c}\text { Ilma- } \\
\text { kuivia } \\
\text { siemeniä } \\
\text { (g) }\end{array}$ & $\begin{array}{l}\text { Siemenen } \\
\text { kuivumi- } \\
\text { nen }(\%)\end{array}$ & $\begin{array}{c}\text { Palkoja } \\
\text { (g) }\end{array}$ & $\begin{array}{c}\text { Ilma- } \\
\text { kuivia } \\
\text { siemeniä } \\
\text { (g) }\end{array}$ & $\begin{array}{c}\text { Siemenen } \\
\text { kuivumi- } \\
\text { nen }(\%)\end{array}$ \\
\hline & Schoten & $\begin{array}{c}\text { Luft- } \\
\text { trockene }\end{array}$ & $\begin{array}{c}\text { Trocknen } \\
\text { des }\end{array}$ & Schoten & $\begin{array}{c}\text { Luft- } \\
\text { trockene }\end{array}$ & $\begin{array}{c}\text { Trocknen } \\
\text { des }\end{array}$ & Schoten & $\begin{array}{c}\text { Luft- } \\
\text { trockene }\end{array}$ & $\begin{array}{c}\text { Trocknen } \\
\text { des }\end{array}$ \\
\hline & & Samen & Samens & & Samen & Samens & & Samen & Samens \\
\hline 62 & 21.58 & 7.91 & 40.3 & 31.68 & 8.40 & 50.7 & 7.87 & 4.31 & 9.6 \\
\hline 51 & 14.99 & 7.20 & 27.8 & 21.95 & 7.65 & 54.4 & 5.99 & 2.69 & 25.7 \\
\hline 44 & 9.89 & 5.83 & 17.4 & 14.16 & 5.23 & 42.8 & 5.04 & 2.07 & 39.1 \\
\hline 37 & 8.27 & 4.49 & 25.0 & 11.01 & 4.06 & 33.9 & 2.55 & 0.99 & 31.7 \\
\hline 33 & 7.14 & 3.42 & 24.5 & 6.87 & 2.32 & 51.3 & 1.47 & 0.38 & 52.4 \\
\hline 25 & 8.48 & 2.61 & 40.8 & 4.79 & 1.50 & 61.8 & 1.94 & 0.52 & 56.3 \\
\hline
\end{tabular}

voimakku den mutoksilla ei ole niinsu rta vaikutusta soijan siemenen muodostukseen, että Norrköpingissä v. $1954 \mathrm{monissa}$ soijajalosteissa ilmennyt siemenkato voitaisiin viedä suuresta pilvisyydestäjohtuneen suhteellisen vähäisen valoisu uden tilille. 
Taulukko 4. Soijapavun kehitys kenttäkokeessa kesällä 1956. Kylvetty 5/6, korjattu 21/9. Tabelle 4. Die Entwicklung der Sojabohne im Feldversuch im Sommer 1956. Gesät am 5.6, geerntet am 21.9.

\begin{tabular}{|c|c|c|c|c|c|c|}
\hline \multirow[b]{3}{*}{$\begin{array}{l}\text { Lajike } \\
\text { Sorte }\end{array}$} & \multirow{3}{*}{$\begin{array}{c}\text { Kukinta } \\
\text { alkoi } \\
\text { Blüte } \\
\text { begann }\end{array}$} & \multirow{3}{*}{$\begin{array}{c}\text { Ensimmäiset } \\
\text { palot } \\
\text { näkyvissä } \\
\text { Die ersten } \\
\text { Schoten } \\
\text { zu sehen }\end{array}$} & \multirow{3}{*}{$\begin{array}{c}\text { Korkeus } \\
\text { cm } \\
\text { Höhe }\end{array}$} & \multicolumn{3}{|c|}{$\begin{array}{l}\text { Sato } 10 \text { yksilöä kohden } \\
\text { Ertrag je } 10 \text { Individuen }\end{array}$} \\
\hline & & & & Palkoja & Siemeniä & Samen \\
\hline & & & & $\begin{array}{l}\text { kpl. } \\
\text { Schoten } \\
\text { St. }\end{array}$ & $\begin{array}{l}\text { kpl. } \\
\text { St. }\end{array}$ & $\begin{array}{l}\mathrm{g} \\
\mathrm{g}\end{array}$ \\
\hline Fiskeby $846-2-1$ & $24 / 7$ & $18 / 8$ & 49 & 4.4 & 5.2 & 0.24 \\
\hline Fiskeby $843-15-4$ & $23 / 7$ & $16 / 8$ & 41 & 12.8 & 18.1 & 0.40 \\
\hline Pando & $29 / 7$ & $22 / 8$ & 29 & 19.4 & 27.8 & 0.39 \\
\hline
\end{tabular}

Taulukko 5. Sääsuhteet Viikin koetilalla kesä-syyskuussa 1956 (Normaaliarvot Helsingistä) ${ }^{1}$ ). Tabelle 5. Die Witterungsverhälnisse auf dem Versuchsgut Wiik Juni-September 1956 (Normalwerte von Helsinki $\left.{ }^{1}\right)$.

\begin{tabular}{|c|c|c|c|c|c|c|}
\hline \multirow{2}{*}{$\begin{array}{l}\text { Kuukausi } \\
\text { Monat }\end{array}$} & \multicolumn{2}{|c|}{$\begin{array}{l}\text { Keskilämpötila } \mathrm{C}^{\circ} \\
\text { Temperaturmittel }\end{array}$} & \multicolumn{2}{|c|}{$\begin{array}{l}\text { Sademäärä mm } \\
\text { Niederschlagsmenge }\end{array}$} & \multicolumn{2}{|c|}{$\begin{array}{c}\text { Pilvisyys } 0-10 \\
\text { Bewölkung }\end{array}$} \\
\hline & 1956 & Norm. & 1956 & Norm. & 1956 & Norm..$^{2}$ ) \\
\hline $\begin{array}{l}\text { Kesäkuu } \\
\text { Juni }\end{array}$ & 15.9 & 13.5 & 18 & 51 & 4.9 & 5.9 \\
\hline $\begin{array}{l}\text { Heinäkuu } \\
\text { Juli }\end{array}$ & 16.0 & 17.1 & 129 & 59 & 5.3 & 5.6 \\
\hline $\begin{array}{l}\text { Elokuu } \\
\text { August }\end{array}$ & 13.2 & 15.2 & 135 & 83 & 5.1 & 5.6 \\
\hline $\begin{array}{l}\text { Syyskuu } \\
\text { September }\end{array}$ & 8.3 & 10.8 & 36 & 73 & 4.5 & 6.7 \\
\hline
\end{tabular}

1) Lämpötila $1901-1930$

Temperatur 1901-1930

Sademääră 1886 - 1935

Niederschlagsmenge 1886-1935

$\left.{ }^{2}\right)$ Keskipilvisyys Helsingissä 1946-1956

Mittlere Bewölkung in Helsinki 1946-1956 
Taulukko 6. Vuosina 1947-53 Viikin koetilalla suoritettujen soijan kenttäkokeiden tuloksia (V. 1953 oli kokeissa myös Pando, mutta siitäkään ei saatu satoa).

Tabelle 6. Ergebnisse der in den J. 1947-53 auf dem Versuchsgut Wiik ausgeführten Feldversuche mit Soja (im J. 1953 war auch Pando in den Versuchen; auch sie gab keinen Ertrag).

V u o n a 1947

Im J. 1947

Siemensato $\left(\mathrm{g} / 4 \mathrm{~m}^{2}\right)$

Samenertrag

1000 siemenen paino $(\mathrm{g})$

1000-Samengewicht

Siemensadon itävyys (\%)

Keimfahigkeit des Samenertrages

Vuonna 1948

Im J. 1948

Siemensato $\left(\mathrm{g} / 4 \mathrm{~m}^{2}\right)$

Samenertrag

1000 siemenen paino $(\mathrm{g})$

1000-Samengewicht

V u o n n a 1949

Im J. 1949

Siemensato $\left(\mathrm{g} / 4 \mathrm{~m}^{2}\right)$

Samenertrag

1000 siemenen paino $(\mathrm{g})$

1000-Samengewicht

Siemensadon itävyys (\%)

Keimfahigkeit des Samenertrages

Vuosina $1950-1953$

Im J. 1950-1953

Siemensato ei tuleentunut

Samenertrag nicht gereift

\begin{tabular}{cc} 
Manitoba & Aro \\
\hline 283 & 570 \\
107 & 139 \\
98 & 94
\end{tabular}

266

440

83

135

22

95

58

97

26

73

Taulukko 7. Kesä-syyskuun keskilämpötila $\left(\mathrm{C}^{\circ}\right)$ ja keskipilvisyys $(0-10)$ Viikin koetilalla vv. $1947-1953$ Tabelle 7. Temperaturmittel Juni-September $\left(C^{\circ}\right)$ und mittlere Bewölkung $(0-10)$ auf dem Versuchsgut Wiik in den J. 1947-1953.

\begin{tabular}{|c|c|c|c|c|c|c|c|c|c|c|}
\hline \multirow[b]{2}{*}{$\begin{array}{l}\text { Vuosi } \\
\text { Jahr }\end{array}$} & \multicolumn{4}{|c|}{$\mathrm{C}^{\circ}$} & \multicolumn{4}{|c|}{$0-10$} & \multicolumn{2}{|c|}{$\begin{array}{c}\text { Soija } \\
\text { Soja }\end{array}$} \\
\hline & VI & VII & VIII & IX & VI & VII & VIII & IX & 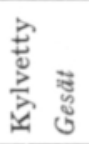 & 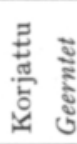 \\
\hline 1947 & 15.9 & 17.7 & 16.8 & 12.7 & 5.0 & 5.4 & 4.1 & 5.9 & 22.5 & $16 / 9$ \\
\hline 1948 & 15.3 & 18.0 & 15.1 & 11.8 & 6.5 & 4.3 & 7.0 & 6.6 & $20 / 5$ & $20 / 9$ \\
\hline 1949 & 13.0 & 17.5 & 15.0 & 14.5 & 7.5 & 5.4 & 6.4 & 5.5 & $15 / 5$ & $20 / 9$ \\
\hline 1950 & 14.5 & 15.7 & 16.9 & 12.3 & 5.6 & 7.1 & 4.1 & 7.7 & $24 / 5$ & $26 / 9$ \\
\hline 1951 & 13.7 & 15.5 & 18.4 & 13.1 & 5.7 & 6.2 & 3.6 & 6.1 & $4 / 6$ & - \\
\hline 1952 & 13.5 & 16.1 & 14.4 & 9.3 & 5.2 & 5.4 & 7.1 & 7.6 & $23 / 5$ & - \\
\hline 1953 & 16.7 & 17.1 & 15.6 & 10.7 & 5.2 & 6.0 & 6.8 & 6.7 & $19 / 5$ & - \\
\hline
\end{tabular}


UBER PHOTOBIOLOGISCHE EIGENSCHAFTEN EINIGER SOJA-ZUCHTSORTEN

Onni Pohjakallio und Simo Antila

Pflanzenpathologisches Institut, Universität, Helsinki

Direktor Sven Holmberg sandte an das Pflanzenpathologische Institut der Universität Helsinki zwei seiner Soja-Zuchtsorten (Fiskeby $843-15-4$ und Fiskeby $846-2-1$ ) sowie die koreanische PandoSoja zur Untersuchung ein. Diese Soja-Sorten erwiesen sich als annähernd tagneutral (Tabelle 1). Bei spärlicher Lichtintensität etiolierten besonders die Fiskeby-Soja-Sorten beträchtlich (Abb. 2), aber auf die Zeitlage der Blüte übte eine Veränderung der Lichtintensität nur eine geringe Wirkung aus (Tabelle 2). Die Soja-Sorten bildeten auch bei recht spärlicher (25\% der Aussenbelichtung) Belichtung gereiften Samen aus (Tabelle 3). Am geringsten war die Wirkung der Änderung der Lichtintensität auf die Menge des Samenertrages von Fiskeby 846-2-1, am stärksten auf die Sorte Pando. In den Feldversuchen gab dagegen Fiskeby 846-2-1 unter diesen Sorten den geringsten Samenertrag (Tabelle 4). Auf grund dieser wie auch der Ergebnisse anderer auf dem Versuchsgut Wiik in Helsinki ausgeführten Versuche (Tabellen 6-7) ist zu schliessen, dass die sommerlichen Belichtungsverhältnisse auf das Gedeihen der in Rede stehenden annähernd tagneutralen Soja-Zuchtsorten unter den in Südfinnland gegebenen Bedingungen kaum einen wesentlichen Einfluss ausüben. Zugleich stützen die Ergebnisse dieser Untersuchungen die von Rudorf (Vgl. Holmberg, s. 113) dargestellte Auffassung, dass die für den Anbau der Soja-Sorten von Fiskeby entscheidende Nordgrenze durch die niedrige Temperatur diktiert ist. 